\title{
DEVELOPMENT AND VALIDATION OF METHAMPHETAMINE ANALYSIS IN SALIVA USING GAS CHROMATOGRAPHY-TANDEM MASS SPECTROMETRY
}

\author{
YAHDIANA HARAHAP ${ }^{1 *}$, MUHAMMAD REZQI HAKIM ${ }^{1}$, KUSWARDANI SOEDIGDO ${ }^{2}$ \\ ${ }^{1}$ Bioavailability/Bioequivalence Laboratory, Faculty of Pharmacy, Universitas Indonesia, Depok, 16424, Indonesia. ${ }^{2}$ BNN's Drugs Testing \\ Laboratory, Jakarta, 12940, Indonesia. Email: yahdiana03@yahoo.com
}

Received: 08 June 2018, Revised and Accepted: 09 August 2018

\section{ABSTRACT}

Objective: The aim of this study was to develop and validate analytical methods for determining methamphetamine in saliva using gas chromatographytandem mass spectrometry (MS).

Methods: The chromatography conditions were DB MS- 5 capillary columns with a length of $30 \mathrm{~m}$, inner diameter of $0.25 \mathrm{~mm}$, mobile phase of Helium gas $99.999 \%$, flow rate of $0.8 \mathrm{~mL} / \mathrm{min}$, detection of MS at m/z values of 58.00 and 91.00 , respectively, and ephedrine $\mathrm{HCl}$ as the internal standard.

Results: The validation of analytical methods for methamphetamine satisfies the validation criteria by the EMEA Guidelines 2011. Bioanalytical methods obtained were linear in the concentration range from 15.0 to $300.0 \mathrm{ng} / \mathrm{mL}$ with $\mathrm{r}>0.9999$. Sample preparation was done using liquid-liquid microextraction with cyclohexane, supernatant residue was dried and reconstituted with approximately $100 \mu \mathrm{L}$ of methanol.

Conclusion: The method was successfully applied to saliva samples of methamphetamine users with levels in the range of test.

Keywords: Methamphetamine, Optimum, Validation, Human saliva, Ephedrine HCl.

(c) 2018 The Authors. Published by Innovare Academic Sciences Pvt Ltd. This is an open access article under the CC BY license (http://creativecommons. org/licenses/by/4. 0/) DOI: http://dx.doi.org/10.22159/ijap.2018.v10s1.20

\section{INTRODUCTION}

Methamphetamine, known as shabu in Indonesia, is a very strong central nervous system stimulant from the amphetamine group [1,2]. To determine the evidence of methamphetamine abuse, a test to detect methamphetamine in the body is required. Methamphetamine levels in the body are usually detected using the blood and urine [1-4]. However, saliva is simpler to obtain and more efficient sample for methamphetamine tests in the body [4].

Narcotics are substances or drugs, derived from herbs or synthetic, that can cause altered levels of consciousness, loss of sensation, reduction in pain, and addiction [1]. Narcotics are also needed to treat certain diseases but, if misused, can be disadvantageous to the person and, moreover, to the community. In the year 2013, the amount of confiscated shabu rapidly increased compared with that in the year 2012 [5]. This shows that methamphetamine is a drug which is used a lot in society.

In Indonesia, drug abuse is a criminal act and needs to be judged by the law; thus, its intake needs to be proven. Until now, urine, blood, hair, and other body part tests have been performed to determine the presence of the drug in the body. The oral liquid or saliva test is a fast and noninvasive alternative to these tests. The main analyte is suspected to not undergo metabolism in the saliva. In addition, while collecting blood samples requires professional skills, collecting saliva does not [6].

Unlike urine samples, saliva can be collected under supervision without disturbing privacy. Most drugs are bound strongly to blood protein, based on the consideration that only free fractions of a drug are pharmacologically active. Saliva contains only a small part of the free fraction of drug. This can be filtrated from the salivary tissue, including the capillary wall, basal membrane, and epithelial cells of salivary glands [6].

Methods to analyze methamphetamine in saliva samples using gas chromatography-tandem mass spectrometry (GC-MS) are still limited. According to other studies, the maximum concentration of methamphetamine in saliva can reach $300 \mathrm{ng} / \mathrm{mL} 4 \mathrm{~h}$ after drug usage, whereas the maximum concentration in blood plasma can reach $35 \mathrm{ng} / \mathrm{mL} 4 \mathrm{~h}$ after usage [7]. Meanwhile, maximum concentration of methamphetamine in urine can reach $4500 \mathrm{ng} / \mathrm{mL} 16 \mathrm{~h}$ after usage [8]. Therefore, an analysis method that is sensitive and selective is needed if saliva is to be used as a biological test sample.

According to a previous research, methamphetamine can be extracted from saliva using a liquid-liquid extraction method. Along with the development of an analysis instrument, the modern analytical chemistry trend has shifted to simplification and minimalization of sample preparation. Currently, many innovative microextraction techniques have been developed which can simplify the sample preparation procedure and increase quality and sensitivity of the analysis. In the previous studies, liquid-liquid extraction was combined with GC, capillary electrophoresis, and high-performance liquid chromatography [9-11]. This technique was suitable for forensic examination of drug abuse using minimal sample volume and short analysis time.

In this study, the aim of this was to determine the concentration of methamphetamine in saliva samples using GC-MS with microextraction methods, using cyclohexane as a solvent extractor and ephedrine $\mathrm{HCl}$ as an internal standard. This method can hopefully be applied in the forensic laboratory to test for methamphetamine abuse.

\section{MATERIALS AND METHODS}

Equipment

GC-MS (Shimadzu GCMS-QP2010 Ultra), equipped with DB-5 MS Capillary Column $(0.25 \mathrm{~mm}$ x $30 \mathrm{~m} ; 0.25 \mu \mathrm{m})$, data processing software (Windows Software) and a computer (HP).Other equipments were microcentrifuge (Spectrafuge 16M), analytical balance (Sartorius), ultrasonic mixer (Mmert, vortex, and micropipette (Eppendorf)

\section{Materials}

Materials used in the research were as follows: Methamphetamine standard (Cerrilant); internal standard ephedrine HCl (NADFC); methanol, cyclohexane, chloroform, and $\mathrm{NaOH}$ were purchased from 
Merck; Aquabidest (Ikapharmindo); control saliva sample, and saliva sample from a drug user (Indonesian National Narcotics Agency).

\section{Standard solution, internal standard, and quality control (QC) solution}

Methamphetamine standard $(0.1 \mathrm{~mL})$ was pipetted into a $10.0 \mathrm{~mL}$ volumetric flask. The substance was dissolved in $2 \mathrm{~mL}$ of methanol; then, methanol was added to the limit of the flask. The concentration of standard solution was $0.01 \mathrm{mg} / \mathrm{mL}$. Ephedrine was used as internal standard and was weighed $5.0 \mathrm{mg}$ and then added to a $5.0 \mathrm{~mL}$ volumetric flask. The substance was dissolved in methanol $(2 \mathrm{~mL})$, and then, methanol was added to the limit of the volumetric flask. The internal standard solution obtained had a concentration of $1.0 \mathrm{mg} / \mathrm{mL}$. The internal standard solution and standard solution were then stored at $4^{\circ} \mathrm{C}$.

\section{Instrumentation and chromatography conditions}

GC was performed at a column temperature of $280^{\circ} \mathrm{C}$ and flow rate of $0.8 \mathrm{~mL} / \mathrm{min}$. The mobile phase used was helium $99.999 \%$. Injection volume was $1 \mu \mathrm{L}$.

The ionization parameters were as follows: Capillary pipe voltage, $3.5 \mathrm{kV}$; ion source temperature, $230^{\circ} \mathrm{C}$, interface temperature, $250^{\circ} \mathrm{C}$; and solvent cut time, $1.5 \mathrm{~min}$. The $\mathrm{m} / \mathrm{z}$ value obtained was the ratio of the main ion molecular weight and product ion molecular weight. The $\mathrm{m} / \mathrm{z}$ values used in the methamphetamine and ephedrine $\mathrm{HCl}$ analyses were 58.00 and 91.00 , respectively.

After determining optimum conditions for methamphetamine analysis, mixed solutions of methamphetamine and internal standard were injected 6 times and coefficients of variation (CV) for retention times and areas under the curve for each substance were then calculated as peak area ratio (PAR), which a CV should be $<2.0 \%$. From this experiment, PAR was obtained with a $\mathrm{CV}$ of $<2.0 \%$ (Table 1 ).

\section{Sample preparation}

Sample preparation was performed with saliva containing methamphetamine. The solvent containing $300 \mu \mathrm{L}$ cyclohexane and $100 \mathrm{ng} / \mathrm{mL}$ internal standard ephedrine $\mathrm{HCl}$ was added into the tube. The tube was sonicated at $55^{\circ} \mathrm{C}$ for

$7 \mathrm{~min}$. The tube was then centrifuged for $5 \mathrm{~min}$ at $3000 \mathrm{rpm}$. The supernatant was pipetted to other tube to be evaporated. The residue was reconstituted with $100 \mu \mathrm{L}$ methanol and mixed by vortex for $10 \mathrm{~s}$. The solvent was subsequently inserted into the autosampler vial, and $1 \mu \mathrm{L}$ of the sample was injected into the GC-MS system (Fig. 1).

\section{Bioanalysis method validation}

The lower limit of quantification (LLOQ) was determined by dissolving the lowest concentration from the methamphetamine calibration curve $(15 \mathrm{ng} / \mathrm{mL})$ until it was halved and then quartered. The concentration of the solution was then calculated by injecting it into the GC-MS. This assay was replicated 5 times. From the calculated concentration, the percentage difference (\% diff) system and CV were obtained with a requirement of $< \pm 20 \%$.
A calibration curve of standard solution was prepared by dissolving the standard solution (methamphetamine, $1000 \mathrm{ng} / \mathrm{mL}$ ) until a concentration of $15-300 \mathrm{ng} / \mathrm{mL}$ was obtained. The methamphetamine solution was then dissolved with saliva to obtain a concentration range of $20-300 \mathrm{ng} / \mathrm{mL}$. The correlation coefficient (r) of the linear regression line equation was calculated to obtain a linearity curve. The result showed that \%diff obtained A was not exceeding $\pm 15 \%$ for all concentrations, except LLOQ. LLOQ value obtained was not exceeding $\pm 20 \%$.

Selectivity of the method was determined by preparing saliva which contained the standard methamphetamine solution at the LLOQ concentration, and then, sample preparation was performed at $15 \mathrm{ng} / \mathrm{mL}$. The value of \%diff and $\%$ CV was not to exceed $\pm 20 \%$. The test was conducted using saliva from six different sources, and for each of these, a blank measurement was done with the LLOQ concentration and replicated twice.

Accuracy and precision were determined by preparing a standard solution of methamphetamine at the concentration of LLOQ, QCL, QCM, and QCH. Sample preparation was performed using saliva, and $1 \mu \mathrm{L}$ of the solution injected to the GC-MS system. Accuracy was calculated from the \%diff value to see the relationship between the concentrations obtained from measurement compare to the actual concentration. The test was conducted within-run and between-run. Accuracy was calculated using at least four concentrations of standard solution, with each of them replicated 5 times. The within-run test was conducted 3 times on at least two different days. Value \%diff and \% CV were not to exceed $\pm 15 \%$ for all concentrations, except LLOQ (not exceeding $\pm 20 \%$ ). Value of recovery was calculated by comparing the area of the extraction result to the area of standard solution of the same concentration

Carryover was performed by preparing the blank saliva solution and samples which contained methamphetamine at upper LOQ (ULOQ). Aliquot from the extraction process of blank saliva $(1 \mu \mathrm{L})$ was injected into the GC-MS system after injecting the standard solution which contained methamphetamine at the concentration of the ULOQ. Peak area of methamphetamine and the internal standard that appeared in the blank was observed. This test was replicated 5 times.

The integrity of dilution was determined by preparing a sample saliva which contained methamphetamine at the concentration of $225 \mathrm{ng} / \mathrm{mL}$. The solution was dissolved with blank saliva until halved and also a quarter of the concentration was acquired. The dilution solution was then prepared, and $1 \mu \mathrm{L}$ of the final solution was injected into the GC-MS system. The test was replicated 5 times to acquire accuracy and precision.

The matrix effect was determined by preparing a blank saliva for sample preparation. The acquired supernatant was then added with methamphetamine of low concentration (QCL) and high concentration $(\mathrm{QCH})$ and, thus, added the internal standard $(100 \mu \mathrm{g} / \mathrm{mL})$. The final solution $(1 \mu \mathrm{L})$ was then injected into the GC-MS system. After that, the standard methamphetamine solution was prepared at low concentration (QCL) and high concentration $(\mathrm{QCH})$ and the internal standard at

Table 1: System suitability test results*

\begin{tabular}{|c|c|c|c|c|c|}
\hline \multirow[t]{2}{*}{ Data No. } & \multicolumn{2}{|l|}{ Retention time (min) } & \multicolumn{3}{|l|}{ Area $(\mu V . s)$} \\
\hline & Methamphetamine & IS & Methamphetamine & IS & PAR \\
\hline 1 & 5.428 & 6.946 & 1025946 & 218530 & 4.6947 \\
\hline 3 & 5.426 & 6.946 & 1022766 & 222863 & 4.5892 \\
\hline 4 & 5.427 & 6.946 & 1035906 & 225997 & 4.5837 \\
\hline 5 & 5.426 & 6.944 & 1027644 & 225618 & 4.5547 \\
\hline 6 & 5.428 & 6.945 & 1026313.6 & 223169 & 4.5993 \\
\hline Mean \pm SD & $5.428 \pm 0.00$ & $6.945 \pm 0.00$ & $1026313.6 \pm 6237.21$ & $223169 \pm 2988.28$ & $4.5993 \pm 0.0549$ \\
\hline CV (\%) & 0.06 & 0.01 & 0.61 & 1.34 & 1.1941 \\
\hline
\end{tabular}




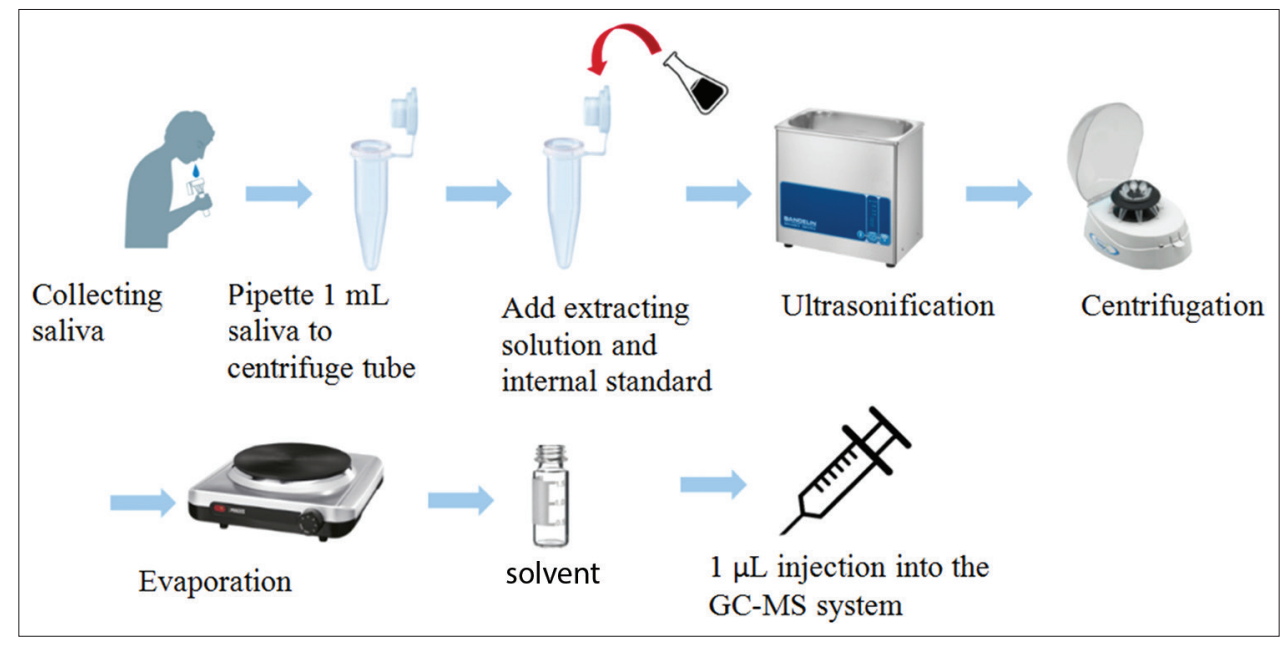

Fig. 1: Working scheme of salivary sample preparation

$100 \mu \mathrm{g} / \mathrm{mL}$. The solution $(1 \mu \mathrm{L})$ was then injected into the GC-MS. The matrix effect was obtained by calculating the matrix factor, which was to compare the peak area of methamphetamine and internal standard within the saliva and the peak area of methamphetamine and internal standard within the standard solution. The matrix factor was normalized by the internal standard and then counted by dividing the matric factor of analyte with the matrix factor of internal standard. The matrix effect was fulfilled the criteria because $\% \mathrm{CV}$ value for each concentration not exceeding $15 \%$.

The stability test included stock solution stability, long-term stability (30 days), and short-term stability $(0,6$, and $24 \mathrm{~h})$ and autosampler stability ( 0 and $24 \mathrm{~h}$ ). For the stock solution stability test, a QC sample of methamphetamine at low and high concentrations was prepared and stored at $-20^{\circ} \mathrm{C}$. For the short-term stability test, saliva was kept at room temperature. Autosampler stability was performed by reserving the sample, which was injected at 0 and $24 \mathrm{~h}$.

\section{RESULTS AND DISCUSSION}

\section{Determining the LLOQ}

The value of LLOQ was determined by preparing a calibration curve of a standard solution with concentrations of $15-300 \mathrm{ng} / \mathrm{mL}$. The $15 \mathrm{ng} / \mathrm{mL}$ concentration of standard solution was considered as the temporary LLOQ and then, this was repeated 5 times. The value of \%diff and CV at the concentration of $15 \mathrm{ng} / \mathrm{mL}$ fulfilled the accuracy and precision criteria, which was $< \pm 20 \%$. Subsequently, the solution was diluted to half $(7.5 \mathrm{ng} / \mathrm{mL})$ and five replicas were made, but the results did not fulfil the criteria.

\section{Linearity/calibration curve}

For analyzing methamphetamine in saliva, a calibration curve was prepared with a range of $15-300 \mathrm{ng} / \mathrm{mL}$. The calibration curve was prepared using blank saliva (saliva without the analyte and internal standard), zero sample (saliva with the internal standard), and non-zero saliva (saliva with the analyte and internal standard) at seven concentrations: $15,30,50,75,100,200$, and $300 \mathrm{ng} / \mathrm{mL}$.

Calibration curve analysis was conducted by looking at the linearity parameter ( $r>0.9990)$ and accuracy (\%diff not exceeding $\pm 15 \%$, except for LLOQ concentration [not exceeding $\pm 20 \%]$ ]). One of the measurements of the calibration curve is shown in Fig. 2. The calibration curve produced the following linear regression equation: $y=0.0004+0.0005 x$ with $r=0.9999$; where $x$ is the methamphetamine concentration $(\mathrm{ng} / \mathrm{mL})$ and $\mathrm{y}$ is PAR between methamphetamine and internal standard ephedrine $\mathrm{HCl}$.

A calibration curve was prepared for every analysis to minimalize the possibility of measurement error because of the changing conditions

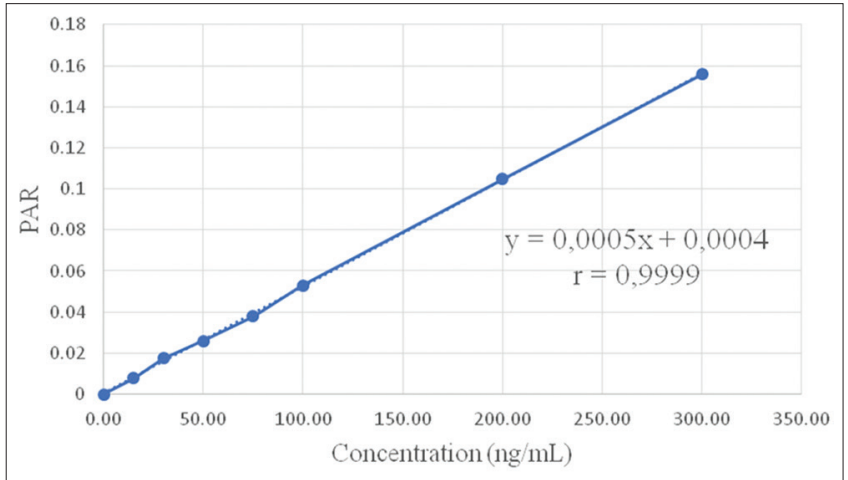

Fig. 2: Methamphetamine calibration curve

of the GC-MS system on different days. Therefore, the calibration curve had to fulfil the precision criteria every time a calibration curve was made, by looking at the $\mathrm{CV}$ value of each of the concentrations of the calibration curves (not exceeding $\pm 15 \%$; except LLOQ which was not exceeding $\pm 20 \%$ ). According to data, the $\mathrm{CV}$ value that was obtained did not exceed $\pm 15 \%$ for all concentrations, including LLOQ with a mean $r$ of 0.9990 (Fig. 2).

\section{Accuracy, precision, and recovery test}

At the within-run measurement of accuracy, the \%diff value obtained for LLOQ concentration was within the range of $-2.07 \%-+7.65 \%$ and for QC concentration was within the range of $-6.10 \%-+6.97 \%$. The within-run measurement of precision obtained a CV value of $<5.14 \%$ for LLOQ and QC concentration. For the within-run measurement, the accuracy obtained for LLOQ concentration was a \%diff value ranging from $-19.81 \%$ to $+18.87 \%$ and for QC concentration was from $-4.43 \%$ to $+8.77 \%$. The between-run for precision the $\mathrm{CV}$ value was $<15.5 \%$. The values of \%diff and CV for the within-run and between-run tests fulfilled the requirements for accuracy and precision.

\section{Carryover}

The result achieved from peak area percentage from blank saliva at methamphetamine retention time $<8.33 \%$ with mean of $5.90 \%$, so it fulfilled the requirement of $<20 \%$. The peak area percentage for blank saliva and ephedrine $\mathrm{HCl}$ retention time was $<0.51 \%$ with a mean of $0.40 \%$.

\section{Dilution integrity}

The methamphetamine solution in the saliva was made with QCH concentration $(225.0 \mathrm{ng} / \mathrm{mL})$. Then, dilution was done to halve the concentration to $112.50 \mathrm{ng} / \mathrm{mL}$ and halved again to $56.25 \mathrm{ng} / \mathrm{mL}$. The 
integrity test for methamphetamine dilution fulfilled the requirements of value \%diff at the half QCH concentration $(-6.48--$ to tion $w$ at the quarter of QCH (-8.30-- to tion w at the quarter was obtained was $2.11 \%$ for half ULOQ and $1.29 \%$ for quarter ULOQ. With this method, it can be concluded that dilution will not influence the accuracy and precision.

\section{Selectivity}

The selectivity test was performed using the analyte with LLOQ concentration $(15 \mathrm{ng} / \mathrm{mL})$ and blank saliva from six different sources. This was done to look at the ability of the analysis method in the quantitative measurement of LLOQ concentration and to observe any interference of blank saliva using different saliva. In this research, the value $\%$ analyte interference was obtained at $8.42-11.61 \%$ and fulfilled the requirement of $< \pm 20 \%$, with a CV for LLOQ of $11.13 \%$. Other than that, the percentage interferences of internal standard ephedrine $\mathrm{HCl}$ was obtained at $0 \%$.

\section{Matrix effect}

The matrix effect of methamphetamine was $80.79 \%$ at QCL and $73.73 \%$ at $\mathrm{QCH}$. That result showed that ionization suppression happened to the analyte which was possibly caused by the existence of many matrices other than the analyte that can disturb the ionization process during MS. The CV value from the analyte fulfilled the requirements of EMEA (CV value achieved from six different saliva sources not exceeding 15\%).

\section{Stability test}

The short-term stability test of the stock solution was conducted for $24 \mathrm{~h}$ at room temperature, and the long-term stability test for 30 days at $4{ }^{\circ} \mathrm{C}$. The results obtained were: \%Diff value for the stability of methamphetamine stock solution in short term: $-0.14 \%$ to $0.16 \%$; and \%diff value for stability for ephedrine $\mathrm{HCl}$ stock solution in short term: $-1.09-1.08 \%$. This result shows that the stock solution of methamphetamine and ephedrine $\mathrm{HCl}$ was stable when kept at room temperature for at least $24 \mathrm{~h}$. For long-term stability, value \%diff for stock solution of methamphetamine was $-0.08-+0.07 \%$ and for ephedrine $\mathrm{HCl}$ was $-1.92--$ to $\%$ and fo days storage at temperature of $4^{\circ} \mathrm{C}$. Based on these results, the stock solution for methamphetamine and ephedrine $\mathrm{HCl}$ can be stored for at least 30 days.

The short-term stability test was performed by storing QCH and QCL at room temperature for $24 \mathrm{~h}$ and then observed for its stability at 0,6 , and $24 \mathrm{~h}$. The \%diff value after $24 \mathrm{~h}$ for QCL concentration starts from 7.21\% up to $9.19 \%$ and for QCH start from $4.47 \%$ up to $9.03 \%$. This showed that methamphetamine in saliva can be kept at room temperature for at least $24 \mathrm{~h}$. The long-term stability test was done by keeping QCL and QCH at $-4^{\circ} \mathrm{C}$ for 30 days and then analyzed at day 0 and day 30 . According to the result, the value \%diff at day 30 of QCL concentration was between $-5.20 \%$ and - nd day This showed that methamphetamine in saliva was stable and can be stored at a temperature of $-4^{\circ} \mathrm{C}$ for at least 30 days.

\section{CONCLUSION}

The developed method for determination methamphetamine in saliva was simple and easy with liquid-liquid microextraction. The method was valid and linear at the concentration range of $15.0-300.0 \mathrm{ng} / \mathrm{mL}$ with $r>0.9999$ and can be applied to saliva samples of methamphetamine users. Furthermore, the stock solution of methamphetamine and ephedrine $\mathrm{HCl}$ was stable when kept at room temperature for at least $24 \mathrm{~h}$ and can be stored for at least 30 days.

\section{CONFLICTS OF INTEREST}

The authors have no conflicts of interest.

\section{REFERENCES}

1. President of Republic Indonesia Decree. Republic Indonesia Decree No. 35 in 2009 About Drugs. $1^{\text {st }}$ ed. Jakarta: Cipta Karya; 2009.

2. United Nations, O. on D. C. Amphetamine, Methamphetamine and their Ring-Substituted Analogues in Seized Materials; 2006. Available from: https://www.unodc.org/pdf/scientific/stnar34.pdf.

3. Nakashima K, Kaddoumi A, Ishida Y, Itoh T, Taki K. Determination of methamphetamine and amphetamine in abusers' plasma and hair samples with HPLC-FL. Biomed Chromatogr 2003;17:471-6.

4. Cheung S, Nolte H, Otton SV, Tyndale RF, Wu PH, Sellers EM, et al. Simultaneous gas chromatographic determination of methamphetamine, amphetamine and their p-hydroxylated metabolites in plasma and urine. J Chromatogr B Biomed Sci Appl 1997;690:77-87.

5. Indonesian National Narcotics Agency. Final National Survey in Development of Drug Abuser in 2004. Jakarta: BNN; 2014.

6. Elmongy H, Abdel-Rehim M. Saliva as an alternative specimen to plasma for drug bioanalysis: A review. Trac Trends Analyt Chem 2016;83:70-9.

7. Schepers RJ, Oyler JM, Joseph RE Jr., Cone EJ, Moolchan ET, Huestis MA, et al. Methamphetamine and amphetamine pharmacokinetics in oral fluid and plasma after controlled oral methamphetamine administration to human volunteers. Clin Chem 2003;49:121-32.

8. Huestis MA, Cone EJ. Methamphetamine disposition in oral fluid, plasma, and urine. Ann N Y Acad Sci 2007;1098:104-21.

9. Meng P, Wang Y. Small volume liquid extraction of amphetamines in saliva. Forensic Sci Int 2010;197:80-4.

10. Bahmanabadi L, Akhgari M, Jokar F, Sadeghi HB. Quantitative determination of methamphetamine in oral fluid by liquid-liquid extraction and gas chromatography/mass spectrometry. Hum Exp Toxicol 2017;36:195-202.

11. Marilyn AH, Edward JC. Methamphetamine disposition in oral fluid, plasma, and urine. Ann N Y Acad Sci 2007;1098:104-21. 